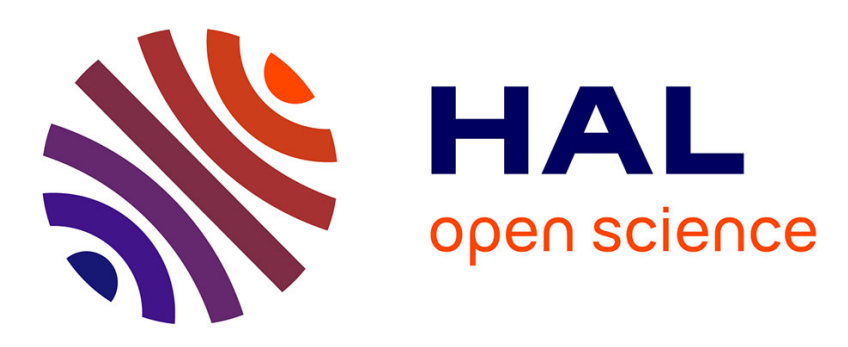

\title{
Identification and characterization of novel potentially oncogenic mutations in the human gene in a breast cancer patient
}

M. Ángeles Villaronga, Irene López-Mateo, Linn Markert, Enrique Espinosa, Juan Ángel Fresno Vara, Borja Belandia

\section{To cite this version:}

M. Ángeles Villaronga, Irene López-Mateo, Linn Markert, Enrique Espinosa, Juan Ángel Fresno Vara, et al.. Identification and characterization of novel potentially oncogenic mutations in the human gene in a breast cancer patient. Breast Cancer Research and Treatment, 2011, 128 (3), pp.891-898. 10.1007/s10549-011-1492-4 . hal-00629080

\section{HAL Id: hal-00629080 https://hal.science/hal-00629080}

Submitted on 5 Oct 2011

HAL is a multi-disciplinary open access archive for the deposit and dissemination of scientific research documents, whether they are published or not. The documents may come from teaching and research institutions in France or abroad, or from public or private research centers.
L'archive ouverte pluridisciplinaire HAL, est destinée au dépôt et à la diffusion de documents scientifiques de niveau recherche, publiés ou non, émanant des établissements d'enseignement et de recherche français ou étrangers, des laboratoires publics ou privés. 


\section{Identification and characterization of novel potentially oncogenic mutations in}

the human BAF57 gene in a breast cancer patient

$\mathrm{M}^{\mathrm{a}}$ Ángeles Villaronga ${ }^{1 *}$, Irene López-Mateo ${ }^{1 *}$, Linn Markert ${ }^{1}$, Enrique Espinosa ${ }^{2}$, Juan Ángel Fresno-Vara ${ }^{3}$ and Borja Belandia ${ }^{1}$

${ }^{1}$ Department of Cancer Biology, Instituto de Investigaciones Biomédicas Alberto Sols, CSIC-UAM, Arturo Duperier 4, 28029 Madrid, Spain

${ }^{2}$ Service of Oncology, IdiPAZ, Hospital Universitario La Paz, Paseo de la Castellana 261, 28046 Madrid, Spain

${ }^{3}$ Laboratory of Molecular Pathology \& Oncology, IdiPAZ, Hospital Universitario La Paz, Paseo de la Castellana 261, 28046 Madrid, Spain

*Ma Ángeles Villaronga and Irene López-Mateo contributed equally to this study and should be considered as co-first authors.

Correspondence: Dr. B Belandia, Department of Cancer Biology, Instituto de Investigaciones Biomédicas Alberto Sols, Consejo Superior de Investigaciones Científicas- Universidad Autónoma de Madrid, Arturo Duperier 4, 28029 Madrid, Spain Tel: +34 91585 4429; Fax: + 3491585 4401; email: bbelandia@iib.uam.es 


\begin{abstract}
BAF57 is a core subunit present in all mammalian SWI/SNF ATP-dependent chromatin remodeling complexes, which regulate important biological processes including gene transcription, DNA recombination, DNA repair and DNA replication. Among other functions, BAF57 mediates the recruitment of SWI/SNF to sequencespecific transcription factors. Thus, BAF57 plays a crucial role in regulating estrogendependent gene expression and proliferation in human cell lines derived from breast tumors. Increasing genetic and biochemical evidences suggest that mutations in BAF57 or alterations in its expression could play and oncogenic role in the mammary gland. Here, we describe two novel mutations in the BAF57 gene found in a breast cancer patient. Both mutations originate premature stop codons, leading to truncated proteins, structurally similar to another BAF57 mutant previously found in a human cell line derived from a breast tumor (BT-549). The expression of these novel BAF57 mutants has abnormally high estrogen receptor alpha (ER $\alpha)$ coactivating potential, suggesting that they might be involved in the aberrant estrogen-dependent proliferation that occur in the majority of breast tumors that retain ER $\alpha$ expression. In addition, the mutations in BAF57 affect its functional interaction with the androgen receptor and ETS2, two transcription factors that play an important role in breast cell biology. Therefore, mutations in BAF57 could impinge on several oncogenic signaling pathways contributing to the origin and/or development of breast cancer.
\end{abstract}

Keywords: BAF57, breast cancer, chromatin remodeling, estrogen receptor, SWI/SNF. 


\section{Introduction}

BAF57 (also known as SMARCE1) is a core subunit present in all SWI/SNF ATPdependent chromatin remodeling complexes in higher eukaryotes [1]. SWI/SNF chromatin remodeling activity is required for the transcriptional regulation of numerous target genes although SWI/SNF complexes also participate in other key biological processes, such as DNA recombination, DNA replication, DNA repair and viral integration [2]. SWI/SNF action requires the proper combinatorial assembly of 10 to 12 subunits. Only one of them (BRG1 or BRM in an exclusive manner) has ATPase enzymatic activity while the other variable associated subunits contribute to the enzymatic activity of the complex and facilitate the recruitment to sequence-specific transcription factors. Perturbations in subunit stoichiometry, or mutations in genes encoding SWI/SNF subunits may contribute to tumorigenesis (reviewed in [3]). Previous results from our laboratory showed that BAF57 plays a crucial role in regulating estrogen-dependent gene expression and proliferation in human cell lines derived from breast tumors [4,5]. BAF57 is an ER subtype-selective regulator that specifically targets estrogen receptor alpha $(\mathrm{ER} \alpha)$, the isoform responsible for mediating estrogen mitogenic signals in more than $60 \%$ of breast tumors that maintain ER $\alpha$ expression. Subsequently, it was demonstrated that BAF57 is critical for androgen receptor (AR) transcriptional activity [6]. The human BAF57 gene maps to chromosome band $17 \mathrm{q} 21$, in close proximity to $B R C A 1$ a locus associated with frequent loss of heterozygosity $(\mathrm{LOH})$ in breast and ovarian cancer [7]. In sporadic breast and ovarian cancers mutations in BRCAI are rare events in samples with $\mathrm{LOH}$ in the region [8], suggesting that other genes in this region may function as tumor suppressors. Therefore, in view of the functional interaction between ER $\alpha$ and BAF57, mutations in BAF57 or alterations in its expression could influence the origin and/or development of breast tumors. A preliminary study looking for mutations in BAF57 in a panel of the most commonly used human breast cancer cell lines led us to uncover a mutation in BAF57 in one of them, BT549, that causes a frame shift leading to a truncated BAF57 protein with altered functionality that behaves as an abnormally potent ER $\alpha$ transcriptional coactivator [9]. We have now extended our study sequencing the BAF57 gene from 95 human primary breast tumors and we have found two new BAF57 mutations in one breast cancer patient that also generate truncated BAF57 proteins, similar to that found 
previously in BT549 cells. Here, we describe the functional characterization of the mutant BAF57 variants and discuss their possible role in breast tumorigenesis.

\section{Materials and methods}

Patients

Tumor samples from 95 patients who had an operation for early-stage invasive breast carcinoma were snap-frozen in liquid nitrogen and kept at $-70^{\circ}$. Median age was 57 years (range 27-80). Frozen sections were stained with haematoxylin and eosin and analyzed by an experienced breast pathologist. Eligible samples had to include at least $70 \%$ of tumor cells. Institutional approval from our ethical committee was obtained for the conduct of the study.

\section{Sample processing}

Total RNA was isolated from frozen sections with TRIzol Reagent (Invitrogen) and cleaned-up with use of the Qiagen RNeasy spin columns. Total RNA isolated was quantified and qualitatively assessed using spectrophotometer $\mathrm{OD}_{260}$ measurements and capillary electrophoresis (Agilent 2100 Bioanalyzer, Agilent). cDNA synthesis was performed using Transcriptor First Strand cDNA Synthesis Kit (Roche) using oligo(dT) $)_{15}$ primers following the manufacturer's instructions.

DNA sequencing

The complete open reading frames of the full-length BAF57 present in the tumor samples were amplified by PCR using $p f u$ DNA Polymerase (Stratagene) with the primers hBAF57e-F ATGTCAAAAAGACCATCTTATGC and hBAF57e-R TTATTCTTTTTTCTCATCTTCTGG. PCR products were fully sequenced by capillary electrophoresis using dye-labeled terminators (3130 Genetic Analyzer, Applied Biosystems). Sequencing primers included the hBAF57e-F and hBAF57e-R described above and the internal primers hBAF57-int-F GCTGAGCGCAGTCAGAGCAGCATC and hBAF57-int-R GCCACATGCCACCAATAATCTTGC. 
Plasmids

The mutated BAF57 open reading frames found in the breast tumor were amplified by PCR and subcloned into pSG5-FLAG (BAF57 BCMUT-A and BAF57 BCMUT-B) or pGEX-6P-1 (GE healthcare, GST-BAF57 BCMUT-A and GST-BAF57 BCMUT-B). The complete open reading frame of the full-length human ETS2 was amplified by PCR using cDNA from MCF-7 breast cancer cells and subcloned into pSG5-FLAG (FLAGETS2) The following plasmids have been previously described: pSG5-hER $\alpha$, pSG5hER $\beta$, pGL3-2ERE-PS2-LUC, pSG5-SRC1e, pSG5-SRC1-bHLH-PAS [5], pSV-AR, TAT-GRE-E1B-LUC [10],

Cell culture and transient transfections

COS-1 cells and MCF-7 cells were cultured in Dulbecco's modified Eagle's medium supplemented with $10 \%$ fetal bovine serum. Twenty-four hours before transfection, cells were plated in 24-well plates in phenol red-free medium with $10 \%$ dextran charcoal-stripped serum. Cells were transfected using Lipofectamine 2000 (Invitrogen). Transfected plasmids are detailed in the figure legends. The amounts of plasmid DNA used were; pGL3-2ERE-PS2-LUC (100 ng/well), TAT-GRE-E1B-LUC (100 ng/well), pSG5-hER $\alpha$ (100 ng/well), pSG5-hER $\beta$ (100 ng/well), pSV-AR (100 ng/well), pSG5BAF57 (wild-type or mutants) (200 ng/well). pRL-TK (5 ng/well) (Promega) was used as internal control for transfection efficiency. All transfection mixtures contained 100 ng/well of pSG5-SRC1e. Cell extracts were assayed for luciferase activity as described previously [10].

GST pull downs assays

Protein-protein interaction assays were performed as previously described [4].

Antibodies

Anti-ER $\alpha$ D12 (Santa Cruz Biotecnology), anti-AR 441 (Abcam), Anti-Flag M2 (Sigma Aldrich). 
Fluorescence analysis

COS-1 cells grown on coverslips were transfected with $100 \mathrm{ng}$ of the plasmids indicated in Fig. 2. After $36 \mathrm{~h}$, cells were fixed with $4 \%$ paraformaldehyde in PBS for $15 \mathrm{~min}$ and permeabilized in $0.1 \%$ Triton X-100 in PBS for 5 min. To perform indirect immunofluorescence cells were incubated in 3\% BSA in PBS for $30 \mathrm{~min}$. Primary immunostaining with mouse anti-Flag antibody (1:500) was carried out at RT for $1 \mathrm{~h}$. Secondary immunostaining with Alexa Fluor 488 goat anti-mouse antibody (InvitrogenA11029) was performed at RT for $1 \mathrm{~h}$. DNA was counterstained with DAPI.

\section{Results}

Identification of mutations in the human BAF57 gene in patients with breast cancer

In order to investigate the possibility that mutations in BAF57 occur in primary tumors from breast cancer patients we sequenced the complete open reading frames present in BAF57 directly from cDNA generated using RNA extracted from frozen tumor sections. 95 patients were included in the study (61 ER positive tumors and 31 ER negative tumors). No mutations were found affecting BAF57 in 94 out of 95 patients, however one of the patients with ER positive breast cancer presented three different BAF57 sequences, one wild type copy and two other heavily mutated copies of the gene that we have named BAF57 Breast Cancer Mutation-A (BAF57-BCMUT-A) and BAF57 Breast Cancer Mutation-B (BAF57-BCMUT-B) (supplementary Fig. 1). Both mutated BAF57 gene copies have many nucleotide changes and they also present a few small deletions. As a result of the sequence variations premature stop codons are introduced at nucleotide 115 (BCMUT-A) or nucleotide 187 (BCMUT-B) giving rise to truncated peptides 38 or 62 amino acids length respectively, considerably shorter than wild-type BAF57 which is 411 amino acids length (Fig. 1a). In addition, the truncated BAF57-BCMUT-A and BAF57-BCMUT-B have three and seven amino acid changes respectively compared to the wild-type protein sequence (Fig. 1b).

Functional characterization of the novel BAF57 breast cancer mutants 
We have previously identified another BAF57 mutation in the BT-549 human cell line, derived from a patient with breast ductal carcinoma [9]. Interestingly, that mutation (BT549-BAF57) generates a truncated peptide lacking most of the C-terminal protein sequence, similar to both novel BAF57 mutants found in the breast tumor (Fig. 1). As expected from such drastic mutation, BT549-BAF57 shows altered functionality. It has lost the capacity to interact directly with ER $\alpha$ but, surprisingly, BT549-BAF57 mutation increased its ability to stimulate transcriptional activation by $\mathrm{ER} \alpha$ in transient transfection experiments [9]. Therefore, we tested the effect of BAF57-BCMUT-A/B expression on the ability of ER $\alpha$ to stimulate transcription from an estrogen-responsive luciferase reporter gene in transfected cells. Expression of both mutants greatly enhanced the activity of ER $\alpha$ while wild-type BAF57 expression had negligible effect and a previously characterized dominant-negative BAF57 deletion mutant ( $\triangle \mathrm{C}$-BAF57) [5] inhibits ER $\alpha$ activity (Fig. 2a, left panel). In keeping with previous results indicating that BAF57 is an ER subtype-selective regulator that specifically targets estrogen ER $\alpha$ [5] we observed that expression of wild-type BAF57 or the mutant variants did not have significant effects on ER $\beta$ activity in a parallel assay (Fig. 2a, right panel). The enhancing effect of both BAF57 mutants on ER $\alpha$ transcriptional activity was also observed in a similar experiment performed using the breast cancer cell line MCF-7 (Fig 2b). Next, we performed indirect immunofluoresce to check the expression of both BAF57-BCMUT in transfected cells. Despite their small size both mutants accumulate to similar levels to those observed for wild-type BAF57 (Fig. 2c). Of note, BAF57BCMUT-A, like wild-type BAF57, shows mostly nuclear localization but BAF57MUT$\mathrm{B}$ is also detected in the cytoplasm.

BAF57 interacts with another steroid receptor, the AR, and this functional interaction is required for androgen-mediated transcription [6]. AR is commonly expressed both in normal mammary tissue and breast cancer cell lines and it is a potential biomarker in breast cancer (reviewed in [11,12]). Hence we tested possible effects of BAF57BCMUTA/B expression on the transcriptional activity of AR in transfected cells. Again, as observed for ER $\alpha$, expression of both BAF57-BCMUT mutants enhanced transcriptional activity of $\mathrm{AR}$ on an androgen-responsive luciferase reporter in abnormally high manner compared to the effect obtained with wild-type BAF57 expression (Fig. 2d). 
Wild-type BAF57 interacts directly with ER $\alpha$ in a ligand-dependent way [4] but the truncated BT549-BAF57 has lost its ability to interact with ER $\alpha$ [9]. To investigate the interaction between BAF57-BCMUTA/B and ER $\alpha$ we performed GST pull-down assays. We found that both breast cancer BAF57 mutants did not interact in vitro with $\mathrm{ER} \alpha$ (Fig. 2e) as expected from their structural similarity with BT549-BAF57. BAF57 also binds to AR [6] and, then again, the extensive deletions in BAF57-BCMUT-A and BAF57-BCMUT-B eliminate the molecular determinants of the direct physical interaction with AR, as shown in the GST pull-down in Fig. 2e. Despite its small size the truncated BT549 mutant still retains the ability to interact with the nuclear receptor coactivator SRC1 [9]. In view of the structural similarity between BT549-BAF57 and the novel BAF57 mutants we carried out GST pull-down assays to investigate the ability of BAF57-BCMUT-A and BAF57-BCMUT-B to interact with the bHLH-PAS domain (amino acids 1-361) of SRC1. These showed that both BAF57 mutations, like wild-type BAF57, were able to interact with the SRC1 bHLH-PAS domain (Fig 2f).

SWI/SNF, together with the transcription factor ETS2, forms a complex that regulates $B R C A 1$ promoter activity [13] and recently it has also been demonstrated that ETS2 participates in a critical signaling pathway that suppresses mammary epithelial tumors [14]. Those observations prompted us to investigate whether BAF57 could be involved in the recruitment of SWI/SNF to ETS2 via direct protein-protein interaction by using in vitro GST binding assays. We found that BAF57 is able to bind ETS2 (Fig. 2g). Moreover, both breast cancer BAF57 mutations completely abolished this interaction (Fig. 2g). The lack of interaction in all GST pull-down assays does not reflect lower expression levels for the mutants because control coomassie-stained gels shown that GST-BAF57-BCMUT-A and GST-BAF57-BCMUT-B express at even higher levels than GST-BAF57 wild type (supplementary Fig. 2).

Taken together, these data indicates that the breast cancer BAF57 mutations have profound effects on its biological functions.

\section{Discussion}

Breast cancer is the most frequently diagnosed type of cancer and the second leading cause of cancer-related death in women in the Western world [15]. The elucidation of the molecular alterations responsible for the origin and progression of this malignancy 
is a critical requirement to discover novel prognostic biomarkers and potential therapeutic targets. In the present study, we identified and characterized two novel mutations in BAF57 in an ER-positive breast primary tumor. These mutations could dysregulate several oncogenic signaling pathways in the mammary gland. First, these BAF57 mutants have abnormally high ER $\alpha$ coactivating potential, suggesting that they might contribute to the estrogen-dependent oncogenic proliferation that occur in the majority of breast tumors that retain ER $\alpha$ expression, like in the case we describe. Moreover, the mutants do not activate ER $\beta$ isoform, which has an anti-proliferative role antagonizing the function of ER $\alpha$ in breast cancer cells [16]. The truncated BAF57 mutants also co-activate in abnormally high manner another sex steroid receptor, the AR. ARs are commonly expressed in normal mammary tissue and approximately $60 \%$ of ER-positive breast tumors also express AR [11,12]. The role of AR during breast tumorigenesis is still unknown, although it is clear that a cross-talk exists between both steroid receptors [12]. In addition, a recent report described that AR expression is a prognostic factor in ER-positive breast cancers, suggesting that AR plays an important role modulating oncogenic signals in breast cancer cells [17]. Thus, mutations in BAF57 may interfere with steroid hormone signaling within breast cells at different levels with potential oncogenic consequences. The truncated BAF57 mutants have lost the ability to interact directly with sex steroid receptors but they are still able to interact with SRC1, a key nuclear receptor coactivator. Therefore, the observed positive effects on ER $\alpha$ and AR transcriptional activity may be mediated by this physical interaction, although the molecular mechanisms for their action are still unknown.

Perturbations in ETS transcription regulatory networks also contribute to breast cancer progression (reviewed in [18]). ETS transcription factors mediate interactions between stromal and epithelial tumor cells and influence the cancer phenotype. ETS2 and SWI/SNF form a repressor complex that negatively regulates the BRCAI promoter in the breast cancer cell line MCF-7 [13]. Also, inactivation of Ets2 in stromal fibroblasts of mouse mammary gland reversed the increased malignancy caused by Pten deficiency [14]. Moreover, expression of ETS2 associate with reduced disease-free survival in breast cancer patients [19]. It was previously described that ETS2 interacts directly with BRG1, the ATPase subunit of the SWI/SNF complex. We have identified a previously unknown interaction between BAF57 and ETS2 that is disrupted by the 
breast cancer mutations in BAF57. Therefore, it is conceivable that the mutations could affect ETS signaling in breast cells.

The tumor expressing BAF57-BCMUTA/B has at least three copies of BAF57, correlating with the frequent chromosomal abnormalities found in the region $17 \mathrm{q} 21$ in breast cancer. The common structure between the previously described BT549-BAF57 and these novel BAF57 mutants suggests that these truncated variants might confer a selective advantage to the breast cancer cells although the molecular events responsible for this advantage have still not been established. More research with breast cancer cell lines expressing the BAF57 mutants is needed to identify the affected signaling pathways. Ultimately, introduction of the BAF57 mutations by Knock-in methods into mouse mammary cancer models, or xenograft experiments in nude mice with genetically modified human breast cancer cell lines will be required to demonstrate their possible oncogenic role in vivo.

Our small-scale screening revealed that only 1 out 95 patients had mutations in BAF57. However, more that one million women are diagnosed with breast cancer annually worldwide and BAF57 mutations could exists in a significant number of patients. Furthermore, to date we have only searched for mutations altering BAF57 sequence. It has been described that changes in the levels of BAF57 alter the proper subunit composition of SWI/SNF [20,21]. Thus, alterations in the copy number of $B A F 57$, not infrequent in the region $17 \mathrm{q} 21$, changing the total protein amount in the cell might also affect BAF57 and/or SWI/SNF functions. Of note, data mining of microarray gene expression using Oncomine ${ }^{\mathrm{TM}}$ (Compendia Bioscience, Ann Arbor, MI) revealed that BAF57 expression was greatly down-regulated in invasive breast carcinoma stroma in a study performed with isolated tumor stroma from clinical breast cancer samples (supplementary fig. 3)[22]. If the inhibition of BAF57 mRNA expression causes a decrease in BAF57 protein levels in those breast tumors, there could be potential oncogenic consequences impinging on ER $\alpha$-, AR- or ETS-signaling or altering other SWI/SNF functions. Further evidence of a link between alterations in BAF57 and breast cancer come from an independent study that has recently shown that there is an association between risk of distant recurrence in breast carcinoma and BAF57 gene copy number [23].

In conclusion, the data here discussed suggests that mutations in BAF57, or aberrant BAF57 expression levels might contribute to the origin and/or progression of a significant number of breast tumors. Due to the low incidence of BAF57 mutations 
found to date in breast cancer patients further analysis of primary tumor biopsies looking for alterations in BAF57 protein expression and sequencing of BAF57 genes for novel mutations will be required to address how clinically relevant are BAF57 alterations in human breast cancer. These studies might also help to understand the molecular events driving breast cell oncogenic proliferation. Therefore, BAF57 may serve as a novel biomarker in breast cancer.

\section{Acknowledgments}

This study was supported by the Ministerio de Ciencia e Innovación (SAF200762642 and SAF2010-21013), Instituto de Salud Carlos III (FIS CP05/00248) and the Fundación de Investigación Médica Mutua Madrileña. We thank Ana Aranda for her continuous support. 


\section{References}

1. Wang W, Chi T, Xue Y, Zhou S, Kuo A, Crabtree GR (1998) Architectural DNA binding by a high-mobility-group/kinesin-like subunit in mammalian SWI/SNF-related complexes. Proc Natl Acad Sci U S A 95 (2):492-498

2. Tsukiyama T (2002) The in vivo functions of ATP-dependent chromatin-remodelling factors. Nat Rev Mol Cell Biol 3 (6):422-429. doi:10.1038/nrm828

nrm828 [pii]

3. Weissman B, Knudsen KE (2009) Hijacking the chromatin remodeling machinery: impact of SWI/SNF perturbations in cancer. Cancer Res 69 (21):8223-8230. doi:00085472.CAN-09-2166 [pii]

10.1158/0008-5472.CAN-09-2166

4. Belandia B, Orford RL, Hurst HC, Parker MG (2002) Targeting of SWI/SNF chromatin remodelling complexes to estrogen-responsive genes. Embo J 21 (15):40944103

5. Garcia-Pedrero JM, Kiskinis E, Parker MG, Belandia B (2006) The SWI/SNF chromatin remodeling subunit BAF57 is a critical regulator of estrogen receptor function in breast cancer cells. J Biol Chem 281 (32):22656-22664

6. Link KA, Burd CJ, Williams E, Marshall T, Rosson G, Henry E, Weissman B, Knudsen KE (2005) BAF57 governs androgen receptor action and androgen-dependent proliferation through SWI/SNF. Mol Cell Biol 25 (6):2200-2215

7. Narod SA, Foulkes WD (2004) BRCA1 and BRCA2: 1994 and beyond. Nat Rev Cancer 4 (9):665-676

8. Futreal PA, Liu Q, Shattuck-Eidens D, Cochran C, Harshman K, Tavtigian S, Bennett LM, Haugen-Strano A, Swensen J, Miki Y, et al. (1994) BRCA1 mutations in primary breast and ovarian carcinomas. Science 266 (5182):120-122.

9. Kiskinis E, Garcia-Pedrero JM, Villaronga MA, Parker MG, Belandia B (2006) Identification of BAF57 mutations in human breast cancer cell lines. Breast Cancer Res Treat 98 (2):191-198

10. Belandia B, Powell SM, Garcia-Pedrero JM, Walker MM, Bevan CL, Parker MG (2005) Hey1, a mediator of notch signaling, is an androgen receptor corepressor. Mol Cell Biol 25 (4):1425-1436

11. Higgins MJ, Wolff AC The androgen receptor in breast cancer: learning from the past. Breast Cancer Res Treat 124 (3):619-621. doi:10.1007/s10549-010-0864-5

12. Somboonporn W, Davis SR (2004) Testosterone effects on the breast: implications for testosterone therapy for women. Endocr Rev 25 (3):374-388. doi:10.1210/er.20030016

25/3/374 [pii]

13. Baker KM, Wei G, Schaffner AE, Ostrowski MC (2003) Ets-2 and components of mammalian SWI/SNF form a repressor complex that negatively regulates the BRCA1 promoter. J Biol Chem 278 (20):17876-17884. doi:10.1074/jbc.M209480200

M209480200 [pii]

14. Trimboli AJ, Cantemir-Stone CZ, Li F, Wallace JA, Merchant A, Creasap N, Thompson JC, Caserta E, Wang H, Chong JL, Naidu S, Wei G, Sharma SM, Stephens JA, Fernandez SA, Gurcan MN, Weinstein MB, Barsky SH, Yee L, Rosol TJ, Stromberg PC, Robinson ML, Pepin F, Hallett M, Park M, Ostrowski MC, Leone G (2009) Pten in stromal fibroblasts suppresses mammary epithelial tumours. Nature 461 (7267):1084-1091. doi:nature08486 [pii]

10.1038/nature08486 
15. Jemal A, Siegel R, Xu J, Ward E Cancer statistics, 2010. CA Cancer J Clin 60 (5):277-300. doi:caac.20073 [pii]

$10.3322 /$ caac. 20073

16. Hartman J, Strom A, Gustafsson JA (2009) Estrogen receptor beta in breast cancer-diagnostic and therapeutic implications. Steroids 74 (8):635-641. doi:S0039$128 \mathrm{X}(09) 00054-3$ [pii]

10.1016/j.steroids.2009.02.005

17. Castellano I, Allia E, Accortanzo V, Vandone AM, Chiusa L, Arisio R, Durando A, Donadio M, Bussolati G, Coates AS, Viale G, Sapino A Androgen receptor expression is a significant prognostic factor in estrogen receptor positive breast cancers. Breast Cancer Res Treat 124 (3):607-617. doi:10.1007/s10549-010-0761-y

18. Turner DP, Findlay VJ, Moussa O, Watson DK (2007) Defining ETS transcription regulatory networks and their contribution to breast cancer progression. J Cell Biochem 102 (3):549-559. doi:10.1002/jcb.21494

19. Redmond AM, Bane FT, Stafford AT, McIlroy M, Dillon MF, Crotty TB, Hill AD, Young LS (2009) Coassociation of estrogen receptor and p160 proteins predicts resistance to endocrine treatment; SRC-1 is an independent predictor of breast cancer recurrence. Clin Cancer Res 15 (6):2098-2106. doi:1078-0432.CCR-08-1649 [pii]

10.1158/1078-0432.CCR-08-1649

20. Chen J, Archer TK (2005) Regulating SWI/SNF subunit levels via protein-protein interactions and proteasomal degradation: BAF155 and BAF170 limit expression of BAF57. Mol Cell Biol 25 (20):9016-9027. doi:25/20/9016 [pii]

10.1128/MCB.25.20.9016-9027.2005

21. Hah N, Kolkman A, Ruhl DD, Pijnappel WW, Heck AJ, Timmers HT, Kraus WL A role for BAF57 in cell cycle-dependent transcriptional regulation by the SWI/SNF chromatin remodeling complex. Cancer Res 70 (11):4402-4411. doi:0008-5472.CAN09-2767 [pii]

10.1158/0008-5472.CAN-09-2767

22. Finak G, Bertos N, Pepin F, Sadekova S, Souleimanova M, Zhao H, Chen H, Omeroglu G, Meterissian S, Omeroglu A, Hallett M, Park M (2008) Stromal gene expression predicts clinical outcome in breast cancer. Nat Med 14 (5):518-527. doi:nm1764 [pii]

$10.1038 / \mathrm{nm} 1764$

23. Davis LM, Harris C, Tang L, Doherty P, Hraber P, Sakai Y, Bocklage T, Doeden K, Hall B, Alsobrook J, Rabinowitz I, Williams TM, Hozier J (2007) Amplification patterns of three genomic regions predict distant recurrence in breast carcinoma. $\mathrm{J}$ Mol Diagn 9 (3):327-336. doi:9/3/327 [pii] 


\section{Figure legends}

Fig. 1 Two novel BAF57 mutations present in one breast cancer patient. a Schematic representation of wild type BAF57 protein, BAF57 truncated proteins encoded by BAF57 mutated genes (BAF57-BCMUT-A and BAF57-BCMUT-B), the artificial dominant-negative deletion mutant $\triangle \mathrm{CBAF57}$ and the truncated BAF57 present in the human BT549 breast cancer cell line (BT549-BAF57). b Multiple alignment of wild type BAF57, BAF57-BCMUT-A and BAF57-BCMUT-B. Protein sequences were aligned by ClustalW2 and formatted with BOXSHADE.

Fig. 2 Functional characterization of naturally occurring breast cancer BAF57 mutants. a BAF57 mutants specifically enhance ER $\alpha$ subtype-mediated transcription. COS-1 cells were co-transfected with expression vectors for ER $\alpha$ (left) or ER $\beta$ (right), the 2xERE-PS2 luciferase vector, SRC1e, wild type BAF57, the dominant negative $\Delta \mathrm{C}$ BAF57 or breast cancer BAF57 mutants (BCMUT-A or BCMUT-B). The results shown represent the averages of the results of four independent experiments assayed in duplicate + s.d. $* P<0.001$ as compared with values for controls (Student's $t$-test). b MCF-7 cells were co-transfected with expression vectors for ER $\alpha$, the 2xERE-PS2 luciferase vector, SRC1e, wild type BAF57, or breast cancer BAF57 mutants (BCMUTA or BCMUT-B). The results shown represent the averages of the results of three independent experiments assayed in duplicate + s.d. $* P<0.01$ as compared with values for controls (Student's $t$-test). In each case ( $\mathrm{a}$ and $\mathrm{b}$ ), after transfection, the cells were washed and incubated for $24 \mathrm{~h}$ in the presence of vehicle (white bars) or $10 \mathrm{nM} 17 \beta-$ estradiol (black bars). Subsequently, cell lysates were assayed using a dual-luciferase reporter system. The normalized values are expressed relative to the activity of ER alone in the presence of $17 \beta$-estradiol. $\mathbf{c}$ Immunofluorescence analysis of the expression pattern of wild type BAF57 and the breast cancer BAF57 mutants. COS-1 cells were transfected with expression vectors for Flag-tagged wild type BAF57, BCMUT-A or BCMUT-B and assayed by indirect immunofluorescence with anti-Flag antibody as described in Materials and Methods. The first column shows the indirect immunofluorescence with anti-Flag antibody (green), the second column shows DAPI staining of DNA (blue), and the third column shows the merge image indicating the degree of colocalization of green and blue fluorescence. Bars, $20 \mu \mathrm{m}$. d COS-1 cells 
were co-transfected with expression vectors for androgen receptor (AR), the TAT-GREE1B luciferase vector, wild type BAF57 or breast cancer BAF57 mutants (BCMUT-A or BCMUT-B). After transfection, the cells were washed and incubated for $24 \mathrm{~h}$ in the presence of vehicle (white bars) or $10 \mathrm{nM}$ dihydrotestosterone (DHT) (black bars). Subsequently, cell lysates were assayed using a dual luciferase reporter system. Normalized values are expressed relative to the activity of AR alone in the presence of DHT. The results shown represent the averages of the results of three independent experiments assayed in duplicate + s.d. $* P<0.001$ as compared with values for controls (Student's $t$-test). e In vitro interaction of BAF57wt, BCMUT-A and BCMUT-B with nuclear receptors. Whole cell extracts from COS-1 cells previously transfected with expression vectors for $\mathrm{ER} \alpha$ or $\mathrm{AR}$ were incubated with GST fusion proteins of BAF57wt, BCMUT-A or BCMUT-B coupled with Sepharose beads in the presence of vehicle (-) or $100 \mathrm{nM}$ hormone (+) (17ß-estradiol or dihydrotestosterone). The associated proteins were detected by western blotting using anti-ER $\alpha$ or anti-AR antibodies. f In vitro interaction of BAF57wt, BCMUT-A and BCMUT-B with SRC1 bHLH-PAS domain (amino acids 1-361). Whole cell extracts from COS-1 cells previously transfected with expression vectors for flag-tagged SRC1 bHLH-PAS domain were incubated with GST fusion proteins of BAF57wt, BCMUT-A or BCMUTB coupled with Sepharose beads. The associated proteins were detected by western blotting using anti-Flag antibody. g In vitro interaction of BAF57wt, BCMUT-A and BCMUT-B with ETS2. Whole cell extracts from COS-1 cells previously transfected with expression vectors for flag-tagged ETS2 were incubated with GST fusion proteins of BAF57wt, BCMUT-A or BCMUT-B coupled with Sepharose beads. The associated proteins were detected by western blotting using anti-Flag antibody. 
a

\begin{tabular}{l} 
P-rich \\
\hline
\end{tabular}

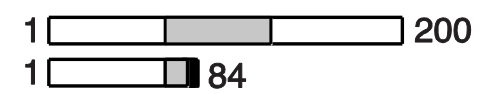

$\triangle$ CBAF57

BT549-BAF57

b

\section{BAF5?}

BAF 57-BCMUT-A

BAP $57-B$ CNUT - B

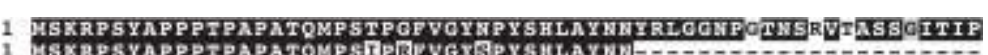

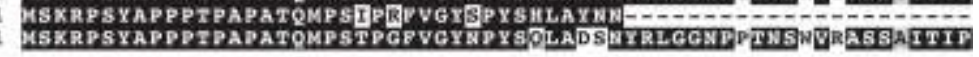

BAF 57

61 WPKPPDKPLMPYMRYSRKVWDQVKASMPDLKLWEI GKI IGGWRDLTDEEKQEYLMEYE

BAF57-BCNUT -

61 医-

BAP 57

121 ARKIEXNESMKAYIRSPAXLAXINARSRARAALEEESRQRQSRMKKGEPYMSIQPAEDPD

BAF57-BCNUT-A
BAF57-BCNUT-B

BAF 57

181 DYDDOFSMKHTATARFQRNHRLISEILSESVVPDVRSVVTTARNQVLKRQVQSLMVHQRK

AP 57-BCNUT -

BAF57-BCNUT-B -

BAF 57

241 LEAELLQIEERHQRKKRKFLESTDSFMBELKRLCGLKVEVDMEKIAAEIAQAEEQARKRQ

BAPS7-BCNUT -

BAP $57-$ BCNUT -1

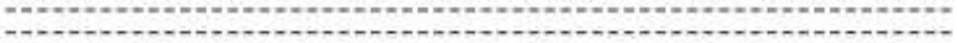

DAF 57

BAF57-BCNUT-A

301 BEREKEAAEQAERSQSSTVPEEgQAAMKGEEKKDDENIPKETEETHLEETTESQQNGEEG

BAF57-BCNUT-B 2.

BAF57

AP $57-B C N U T-A$

361 TSTPEDKESGQEQVDSMAEEQTSDSMTOSESNSATVEEPPTDPIPEDEKKE

BAF $57-$ BCNUT - B (1) 
a

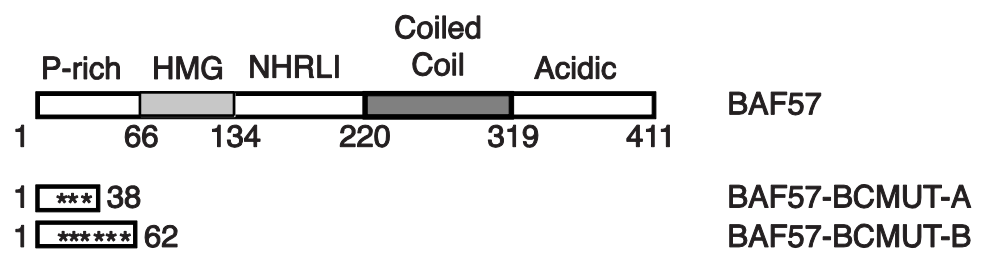

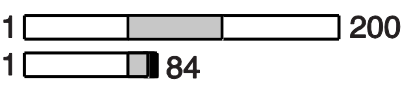

$\triangle$ CBAF57

BT549-BAF57

b

BAF 57

BAF 57 -BCMUT -

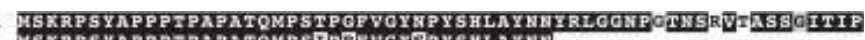
BAF $57-B C N U T-B$

BAF 57

BAF57-BCNUT-A

BAP57-BCNUT -1

61 DPKPPDKPLMPYMRYSRKVWDOVKASMPDLKLWEIGKI IGGMWRDLTDEEKOEYLMEYE

BAP 57

61 这-

BAF 57 - BCNUT - A

121 ABXIEXWESMKAYMASPAXLAXIKAKSRAEAALEEESRQRQSRMEKGEPYMSIQPAEDPD

F57-BCNUT-B

-

BAF57

181 DYDDOF SMKHTATARFQRNHRL ISEILSESVVPDVRSVVTTARNQVLKRQVQSLNVHQRK -

BAF 57

241 LEAELLQIEERHOEKKRKFLESTDSFMGELKRLCGLKVEVDKEKIAAEIAQAEEQARKRO

BAF 57 - BCNUT $-\pi$

-

BAF 5 ?

301 GEREKEAAEQAERSQSSTVPEERQAAKKGEEKKDDENIPKETEETULEETTESQQNGEEG

BAF57-BCNUT -A

BAF57-BCNUT-B

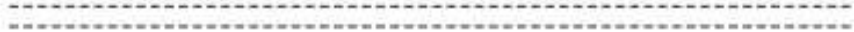

BAF57

361 TSTPEDKESGQEQVDSMAEEQTSDSGTOSESNSATVEEPPTDPIPEDEKKE

BAF 57 -BCNUT - B

TSTPEDKESGQEQVDSMAEEQTSDSUTOSESNSATVEEPPTDPIPEDEKK 